\title{
Farmers' and AI Technicians' Characteristics and Their Impact on AI Technology Adoption, Utilization and Its Efficiency in Ethiopia
}

\author{
Kassahun Melesse $^{1^{*}} \quad$ Ashenafi Mengistu ${ }^{1} \quad$ Driba Geleti $^{2}$ \\ 1.Addis Ababa University, College of Veterinary Medicine and Agriculture, Debre Zeit, Ethiopia \\ 2.Ethiopian Institute of Agricultural Research, P.O.Box 2003, Addis Ababa, Ethiopia
}

\begin{abstract}
The AI delivery system in Ethiopia constrained with various technical, infrastructural and financial problems and thus it is said to be inefficient in terms of genetics and productivity improvement. A study conducted in 2017,2018 and 2019 in Amhara, Oromia, Southern Nations Nationalities and Peoples (SNPP) and Tigray regional states of the country to provide information on the impact of farmers' and AI technicians characteristics that influence the adoption, utilization and efficiency of Artificial Insemination (AI) technology in Ethiopia. The overall mean age of AI technicians in the four studied regions was about 35 years. The total number of AI technicians in 2017/18 was 1,293 of which $93(7.2 \%)$ were female. The engagement of women in the AI delivery system increased in $2017 / 18$ from $1.8 \%$ to $7.2 \%$. About $42 \%$ of the total AI technicians considered in this study trained for 45 days while the other $22 \%, 32 \%$, and $7 \%$ trained for a period of three, six and nine months, respectively. AI technicians in the four study regions served as AI technician for an average of 8.17 years. Experience of AI technicians was positively correlated with the number of inseminations during regular $(\mathrm{r}=0.144)$, peak $\left(\mathrm{r}=0.159^{*}\right)$ and off $\left(\mathrm{r}=0.219^{* *}\right)$ seasons. However, it was found to be negatively correlated with service per conception $(\mathrm{r}=-0.034)$. The average dairy farming household's family size in the four studied regions was 6.18 persons per household. Total household income, income from livestock sale and livestock products was significantly different $(p<0.05)$ among the four regions.
\end{abstract}

Keywords: Adoption, Experience, Extension, Households,

DOI: $10.7176 / \mathrm{JCSD} / 58-01$

Publication date: April $30^{\text {th }} 2020$

\section{INTRODUCTION}

In a country, such as Ethiopia, where there is huge cattle population, the dairy sector can significantly contribute to the wellbeing of the dairying households, the nutrition of consumers, and the economy of the country at large. However, the sector is challenged by technical, infrastructural and policy constraints (Wytze et al., 2012). With the available about 60.4 million heads of cattle and 6.7 million dairy cows (CSA, 2018), the country couldn't be self-sufficient in milk production, rather it has been investing significant sum of foreign currency for importing milk and milk products. Though it is now close to six decades since crossbreeding activities were started in Ethiopia, the proportion of both hybrid and exotic breeds is not greater than $2 \%$ out of 60.4 million heads of cattle (CSA, 2018). This is an indication for the inefficient AI service delivery system in the country.

The success of AI can ultimately be measured by the increase in the number of crossbred dairy animals and an increase in milk production (Ntombizakhe, 2002). Numerous factors mentioned by several scholars for the inefficiency of AI delivery system in the country. The major ones include: lack of the necessary inputs and equipment, unreliable supply of liquid nitrogen, poor quality of semen, lack of basic equipment, inadequate infrastructure, and poor coordination and management system. Lack of motivation and high turnover rate of AI technicians, lack of incentives, lack of recognition for AI technicians, intermittent service delivery system which is off during off working-hours during weekdays, weekends and holidays are also important factors. Moreover, lack of proper record-keeping at the farm level can also be considered as an important factor affecting the country's dairy breed improvement endeavors (Desalegn et al., 2009; Gebregiorgis et al., 2016; Tessema and Atnaf, 2015; Zerihun et al., 2013). As indicated by Pankaj and Nayaran (2016), knowledge on factors affecting the adoption of agricultural technologies will help in enhancing the process of need-based and demand-driven technology generation and then facilitate the adoption of technologies. There are a number of factors that influence the extent of adoption of technology such as characteristics or attributes of technology; the adopters, which is the object of change; the change agent (extension worker, professional); and the socio-economic, biological, and physical environment in which the technology take place (Audrey, 2014). On top of this, it is believed that farmers' and AI technicians' characteristics have significant impact on the adoption, utilization and efficiency of AI technology. However, such characteristics are not well studied and documented. Therefore, the objective of this study is to identify major farmers' and AI technicians' characteristics that can influence AI technology adoption and utilization, and to provide information and recommendations that help to revise the current policy in relation to crossbreeding activity. 


\section{MATERIALS AND METHODS \\ Study Areas}

The study was conducted in four major regions of the country namely Amhara, Oromia, Southern Nations Nationalities and Peoples (SNNP) and Tigray Regions. These regions were purposively selected due to their long experience in AI service delivery and their potential for dairy production. About 16.1 million, 24.4 million, 11.9 million and 4.8 million cattle reported to be available in Amhara, Oromia, SNNP and Tigray regions, respectively (CSA, 2018).

\section{Study Method}

The study was mainly conducted using a face to face interview method with both farmers and AI technicians using a structured questionnaire.

AI technicians survey was conducted in July 2017 and in March 2019 with randomly selected sample AI technicians operating in Amhara, Oromia, SNNP and Tigray regions. A total of 161 AI technicians from the four regions (49 from Amhara, 53 from Oromia, 36 from SNNP and 23 from Tigray regions) were randomly selected and interviewed using a structured questionnaire to collect the required qualitative and quantitative data.

In July 2018, a survey was conducted with farmers from the four target regions: Amhara, Oromia, SNNP and Tigray regions. Sample farmers were randomly selected from a list of farmers who received AI from October 2016 to June 2018. The sample size was determined using the following formula as stated in (Guilford and Frucher, 1973).

Where:

$$
n=N /\left(1+N e^{2}\right)
$$

$\mathrm{n}$ is the required sample,

$\mathrm{N}$ is the population size and

$\mathrm{e}$ is the level of precision $(10 \%)$

Thus, a total of 419 farmers from the four regions (Amhara $=106$, Oromia $=104, \mathrm{SNNP}=105$ and Tigray 104) was randomly selected and interviewed on the issues related to dairy farming household characteristics and dairy cattle farm management practices and AI technology utilization.

\section{Data Analysis}

Primary data collected from AI technicians and farmers through the survey tools entered in Microsoft Excel and Statistical Package for Social Science (SPSS) version 20 (SPSS, 2011). For data analysis, both SPSS and Statistical Analysis System (SAS - Version 9) (SAS, 2004) were used based on the type of variable. For quantitative data, the General Linear Model (GLM) of the SAS was used and means within the same category were separated using the Least Significant Difference (LSD) for those F tests that declared significance $(\mathrm{P}<0.05)$.

\section{RESULTS AND DISCUSSION}

\section{Characteristics of AI Technicians}

The success of AI service is influenced by factors related to the inseminator, the environment, and the animal to be inseminated. Age, educational status, training and experience of AI technicians are among factors related to AI technicians that can influence the efficiency of insemination services. Thus, it is pertinent to assess these characteristics and correlate them with some AI service performance indicators.

\section{Gender of AI technicians}

Of the total 1,361 AI technicians available in the four regions in 2016/17 only 1.76\% were female. Only in Amhara region, higher proportion $(8 \%)$ of women AI technicians engaged in the AI service delivery system. The proportion of women increased to $7.2 \%$ in $2017 / 18$ through the financial and technical support from Land O'Lakes International Development Fund-Public-Private Partnership for Artificial Insemination Delivery (PAID) project following gender barrier analysis conducted in 2016. Though much efforts made to increase the involvement of women in AI service delivery, the increase shown in 2017/18 was not significant. This demonstrates AI service is predominantly men's job in the studied regions and the country at large. It is beyond the scope of this study to identify factors that hinder women in the AI service delivery system. However, previous research results (published and unpublished) demonstrated that cultural, religious and biological factors play a significant role in hindering women from engaging themselves in AI service delivery system. AI service by women AI technicians is not culturally appreciated as it is dealing with reproductive organs. It is believed in most communities that women lack the required physical fitness to properly perform AI and related services. Extended maternity leave provided to them during pregnancy and after birth prevent women AI technicians from continuously delivering AI service Land O'Lakes (2016, Unpublished). A study conducted by Peter et al. (1992) suggested that female AI technicians had significantly more musculoskeletal disorders due to AI work and thus they have higher probability to be off from their job as it takes longer time to recover from this problem and this biological difference can be an evidence 
for the low level of women engagement in AI service delivery system apart from the socio-cultural problems. Low level of women engagement in the AI service delivery is reported in the Philippines (Ybañez et al., 2017) where only $8 \%$ of AI technicians were female in 2015. According to a report by Galv med (2011), nearly all artificial insemination technicians in Africa were men.

\section{Age of AI Technicians}

The average age of AI technicians in Amhara, Oromia, SNNP and Tigray regions was 31.69, 35.43, 35.72 and 37.52 years, respectively with an overall mean age of about 35 years. The age of AI technicians was significantly $(p<0.05)$ lower $(31.69$ years) in Amhara region than in the other three regions among which no significant difference $(p>0.05)$ existed. According to OECD (2019), the working-age population is defined as those aged between 15 and 64. As per this definition, the mean age of AI technicians in the present study falls in the middle of the working-age group. This clearly shows that AI technicians available in the four regions can perform their duties and responsibilities without age-related difficulties. Correlation analysis revealed that age was positively correlated with duration of training $\left(\mathrm{r}=0.387^{* *}\right)$, experience of $\mathrm{AI}$ technicians $\left(\mathrm{r}=0.667^{* *}\right)$, number of inseminations per day during regular $\left(\mathrm{r}=0.163^{*}\right)$, peak $(\mathrm{r}=0.144)$ and off $\left(\mathrm{r}=0.165^{*}\right)$ seasons.

Age is not the only parameter for effective AI service delivery system, gender, experience, health and educational status of AI technicians are among factors that can influence the efficiency of AI service. The mean age of AI technician reported in the present study agrees with other research reports conducted on the characteristics of AI technicians in Philippines (Ybañez et al., 2017), Algeria (Souames et al., 2015) and Sri Lanka (Alexander et al., 1998) where that majority of AI technicians fall between 20 and 40 years of age.

\section{Educational Status of AI Technicians}

The majority $(48.45 \%)$ of AI technicians were diploma $\left(10^{\text {th }}\right.$ or $12^{\text {th }}$ grade plus two or three years of training) holders whereas $29.19 \%$ were first-degree holders (in any discipline) and $19.88 \%$ were certified either as AI technician with a period of up to 9 months training or with other kind of short term (less than one year) pieces of training from vocational and technical schools (Table 1). In Tigray and SNNP regions, almost 95\% of the AI technicians had a diploma and above levels of education. This figure in Amhara and Oromia regions was $49 \%$ and $85 \%$, respectively.

Table 1. Educational status of AI technicians in Amhara, Oromia, SNNP and Tigray regions (2017)

\begin{tabular}{|c|c|c|c|c|c|}
\hline & $\mathrm{N}$ & Secondary Education & Certificate & Diploma & Degree and above \\
\hline Amhara & 49 & - & $25(51.02)$ & $19(38.78)$ & $5(10.20)$ \\
\hline Oromia & 53 & $4(7.55)$ & $4(7.55)$ & $22(41.51)$ & $23(43.40)$ \\
\hline SNNP & 36 & - & $2(5.56)$ & $23(63.59)$ & $11(30.56)$ \\
\hline Tigray & 23 & - & $1(4.35)$ & $14(60.87)$ & $8(34.78)$ \\
\hline Total & 161 & $4(2.48)$ & $32(19.88)$ & $78(48.45)$ & $47(29.19)$ \\
\hline
\end{tabular}

Numbers in parenthesis are percentages

In March 2019, a similar survey was conducted with AI technicians to further investigate and understand the change in their level of education over time. The survey was also aimed at understanding whether AI technicians' diploma or degree level of education is related to livestock science. Only $3(5 \%)$ of 56 AI technicians with degree and diploma level of education studied livestock-related science in Amhara region, 37 (47\%) of 78 in Oromia region, 22 (45\%) of 49 in SNNP region and 19 (38\%) of 50 in Tigray region. Overall, 35\% of AI technicians (19 of 50) with degree and diploma level had livestock-related educational background.

As shown in Table 2 below there was no significant change in the level of education from 2016 to 2019 except in Amhara region where a significant number of AI technicians transited from certificate to diploma level. This might be related to the high turnover rate of AI technicians as they may not be remained in their position once upgraded their education. This is further confirmed in the present study that only $35 \%$ of AI technicians with degree and diploma level of education ( $28 \%$ from the total) studied livestock-related science. If they don't study livestock-related science, they will look for another job and leave their AI duty. Upgrading the educational level of AI technicians in livestock-related sciences can be considered as one way of keeping them in their AI service delivery position. A higher proportion of AI technicians who attended some level of college studies is reported in the Philippines (Ybañez, 2017).

The education level of AI technicians was negatively correlated with the number of insemination services per day per AI technician during regular season $(\mathrm{r}=-0.135)$ and peak season $(\mathrm{r}=-0.062)$ for AI service. This clearly shows experience rather than education can significantly affect the performance of AI technicians. Therefore, maintaining experienced AI technicians in their service delivery position have paramount importance to bring the desired result in the crossbreeding program being implemented in the country. 
Table 2. Educational status of AI technicians in Amhara, Oromia, SNNP and Tigray regions (2019)

\begin{tabular}{lccccc}
\hline \multicolumn{1}{c}{ Regions } & $\mathrm{N}$ & Secondary Education & Certificate & Diploma & Degree and above \\
\hline Amhara & 86 & $2(2.33)$ & $28(32.56)$ & $53(61.63)$ & $3(3.49)$ \\
Oromia & 86 & - & $8(9.30)$ & $41(47.67)$ & $37(43.02)$ \\
SNNP & 66 & - & $17(25.76)$ & $27(40.91)$ & $22(33.33)$ \\
Tigray & 51 & - & $1(1.96)$ & $32(62.75)$ & $18(35.29)$ \\
\hline Total & 289 & 2 & $54(18.69)$ & $153(52.94)$ & $80(27.68)$ \\
\hline
\end{tabular}

Numbers in parenthesis are percentage

\section{AI Technicians' Training}

The duration of AI technicians' training ranged from 45 days to nine months (Table 3 ). About $42 \%$ of the total AI technicians considered in this study trained for 45 days; while the other $22 \%, 32 \%$, and $7 \%$ of them were trained for a period of three, six and nine months, respectively. In Amhara, the highest (47\%) proportion of AI technicians were trained for six months, however, in the remaining three regions, the highest proportion of AI technicians were trained for only 45 days. Only $6 \%$ and $17 \%$ of AI technicians in Oromia and Tigray regions were trained for nine months. No one was trained for 9 months as AI technician in SNNP region.

Table 3. Duration of AI technicians training in Amhara, Oromia, SNNP and Tigray regions

\begin{tabular}{cccccc}
\hline Region & 45 days & Three months & Six months & Nine months & Total \\
\hline Amhara & $4(8.16)$ & $22(44.90)$ & $23(46.94)$ & - & 49 \\
Oromia & $36(67.92)$ & $4(7.55)$ & $10(18.87)$ & $3(5.66)$ & 53 \\
SNNP & $19(52.78)$ & $2(5.56)$ & $15(41.67)$ & - & 36 \\
Tigray & $8(34.78)$ & $7(30.43)$ & $4(17.39)$ & $4(17.39)$ & 23 \\
\hline Total & $67(41.61)$ & $35(21.74)$ & $52(32.30)$ & $7(4.35)$ & 161 \\
\hline
\end{tabular}

Numbers in parenthesis are percentage

The National Artificial Insemination Center (NAIC) has been serving as the major AI technicians' training center since its establishment in 1981. Currently, the training is being given regionally by regional Artificial Insemination centers in Amhara, Oromia, SNNP and Tigray regions and Agricultural, Technical, Educational and Vocational Training (ATVET) Institutes. About 12\% of Amhara, 34\% of Oromia, 19\% of SNNP and 96\% of Tigray AI technicians were trained at NAIC. On the other hand, $67 \%$ of Amhara and $55 \%$ of Oromia AI technicians got AI training at regional AI centers. The proportion of AI technicians trained at ATVETs in Amhara, Oromia, SNNPR and Tigray regions was $20 \%, 11 \%, 81 \%$ and $4 \%$, respectively with the average value being $29 \%$.

The present study confirms that the presence of a wide difference in the duration of training in AI technique which was ranged from 45 days to 9 months and most AI technicians (42\%) in the four regions trained for 45 days (6 weeks). The wide variability in the training duration might be related to the absence of standard AI training curriculum at a national level for decades. There was no accredited institute in the country following a uniform module for AI training to produce efficient AI technicians. However, with the support of a Land O'Lakes - PAID project, the existing training curriculum was reviewed, upgraded and distributed nationally to be used as a standard curriculum in the AI technicians' training. The duration of training in this standard curriculum is 45 days. Though there is a wide difference in the duration of AI training, it seems enough when compared with other countries' training duration such as Uganda where the training lasts 2 to 12 weeks (Camilla, 2013). The duration still cannot be considered as a single factor that results in skilled and efficient AI technicians. The relationship between the duration of training and performance of AI technicians is not established in the present study as it is beyond the scope of the study. However, it is vital to establish such relationship which can help to revise the training duration if there is a positive or negative correlation. Accreditation of training institutes will play a significant role in producing skilled AI technicians. Therefore, training institutes need to be accredited by the concerned body.

Apart from the duration of training, due emphasis should be given to the criteria used to select candidate AI technicians for AI training. Previous knowledge on the anatomy and physiology of female cattle reproductive system determines the duration. Competing $12^{\text {th }}$ grade, $10^{\text {th }}$ grade with level I, level II or level III technical education in the ATVETs were the primary criteria used in regional bureaus to select candidate AI technicians. Such candidates might take a longer time to understand the anatomy and physiology of female cattle reproductive system. This knowledge should be taken into consideration while fixing the duration of the AI training. In some parts of the continent and other parts of the world, veterinary background is still considered as criteria while selecting candidate AI technicians. Such candidates might complete the training within a short period (sometimes two to four weeks) as they can easily understand the physiology of the female reproductive system.

Regional AI centers were found to be the major training site for AI technicians in Amhara and Oromia regions. About $96 \%$ of AI technicians in Tigray region trained at NAIC. In SNNP $80 \%$ of the AI technicians trained at ATVETs. This clearly shows there is no specific place and standard assigned for AI and related trainings. This is confirmed by visiting the training sites which is conducted during the data collection period. The number of 
animals to be used for practical AI training purpose was not standardized. The number of animals determined by the availability of both budget and the required type of animals in the market. The training sites did not have similar capacity in terms of AI training facilities and equipment. They were not fully equipped with AI training materials especially of modern facilities. This lack of uniformity might create a significant difference in the performance of AI technicians. Thus, it is required to equip the training sites with all required facilities and inputs including live animals for practical training purposes. Regional training centers are currently equipped with training dummy cows which can significantly minimize the required number of animals for practical purpose. Generally, all the processes and procedures in the AI training need to be standardized across the country.

\section{Experience of AI Technicians}

One of the major factors for the success of AI service delivery system is the experience of AI technicians. As the experience increases efficiency significantly improves. AI technicians in Amhara, Oromia, SNNP and Tigray regions served as AI technicians for 6.6, 7.8, 9.7 and 10 years, respectively with an overall average experience of 8.2 years. No significant difference $(p>0.05)$ was observed in the experience of Amhara and Oromia region AI technicians. Similarly, the experience among Oromia, SNNP and Tigray region AI technicians was not significant $(p>0.05)$. The experience of Amhara region AI technicians was significantly lower $(p<0.05)$ than SNNP and Tigray region technicians. The maximum (21 years) experience was observed in SNNP region. Experience of AI technicians was positively correlated with the number of inseminations during regular $(\mathrm{r}=0.144)$, peak $\left(\mathrm{r}=0.159^{*}\right)$ and off $\left(\mathrm{r}=0.219^{* *}\right)$ seasons. However, it was found to be negatively correlated with service per conception $(\mathrm{r}=-$ $0.034)$.

The analysis confirms that age was positively correlated with the experience of AI technicians. This does mean as AI technicians remain in their position for years, they will become more experienced in their position. However, the turnover rate of AI technicians in Ethiopia was high as understood from FGDs conducted with regional bureau staff. The positive correlation between age and experience can be interpreted in terms of efficiency of AI technicians as experienced AI technicians can be efficient in their service delivery. The positive correlation between age and experience in this study agrees with previous research reports that indicated experienced technicians performing better than the non-experienced AI technicians (Senger et al., 1984; Roque, 2011; Souames et al., 2015; Kinyua, 2016; Ybañez et al., 2017). Thus, strategies need to be designed and implemented to motivate and retain AI technicians in their position and further studies should identify factors contributing to the high turnover rate of AI technicians in the country.

AI technicians in the four studied regions served for an average of 8.2 years. The present study also demonstrates that the experience of AI technicians was positively correlated with the number of inseminations during regular $(\mathrm{r}=0.144)$ peak $\left(\mathrm{r}=0.159^{*}\right)$ and off $\left(\mathrm{r}=0.019^{* *}\right)$ seasons. The average experience of AI technicians reported in this study seems relatively agrees with the report of Alexander et al. (1998) but lower when compared to research report conducted in Uganda where majority of AI technicians had about 11 to 15 years of experience (Camilla, 2013) in AI service delivery system. However, the positive correlation reported in this study agrees with Souames et al, (2015) where they reported similar relationships in Algeria which was explained by a significantly higher number of AI services performed by experienced AI technicians when compared with the non-experienced AI technicians.

In contrary to the positive relationship between experience and the number of AI services, the present study demonstrates a negative correlation $(\mathrm{r}=-0.034)$ between experience and service per conception. This might be related to the problem of lack of enough data on the status of AI services provided to client farmers. If follow up visits properly undertaken to check the outcome of AI services provided, the correlation between experience of AI technicians and service per conception would be different from the present result. Therefore, further research is needed to establish a relationship between experience and service per conception.

\section{AI Technicians' Job Satisfaction}

AI technicians were interviewed with the intention of understanding whether they are satisfied with their job and the salary they were being paid, if they had plan to change their job and if they were delivering off-hour (especially night-time) services when requested. Accordingly, about $99 \%$ of the technicians in the four regions $(100 \%$, in Amhara, SNNPR and Tigray regions and $96 \%$ in Oromia) reported that they like their job but only $8.75 \%$ of the technicians (2\% in Amhara, 11\% in Oromia, 17\% in SNNPR and 4\% in Tigray) were satisfied with their monthly salary.

About $33 \%$ of the technicians (26\% in Amhara, $42 \%$ in Oromia, $9 \%$ in SNNPR and $65 \%$ in Tigray) had plan to change their job due to various reasons with the major ones being the very low monthly salary they earn, and demotivating carrier structure implemented in their respective regions. The highest $(65.2 \%)$ number of AI techs planning to change their job was reported in Tigray region. On average, $38 \%$ of technicians complained that they were forced to accomplish other assignments given by their respective woredas with the highest (70\%) proportion being in the Oromia region. 
About one third (33\%) of the technicians were not satisfied with their job and thus had plan to change their position due to various reasons most importantly of the minimum salary rate and demotivating carrier structure implemented in their respective regions. Unavailability of the required equipment and inputs especially of motorbike and fuel were among the challenges could demotivate AI technicians to stay in their job. The present data demonstrates the degree of AI technicians' turnover rate. As they become more educated, they will look for a better job with relatively high income. The highest (65\%) job dissatisfaction rate was reported in Tigray region. This might be related to their better level of education as compared to other regions. Unlike other studied regions about $95 \%$ of the technicians in Tigray region were educated to diploma and above level in livestock production or other disciplines thus they were in search of other better positions in their office or outside. Higher-level job dissatisfaction than the present finding reported by Zerihun et al. (2013) in Amhara region where 99\% of AI technicians were dissatisfied with their job as AI technician.

\section{Characteristics of Farmers}

The adoption of agricultural technologies is influenced by age, education level and gender of the farmer, household income, farm size, farming experience, frequency of contact with extension or source of information. Therefore, it is pertinent to collect relevant data and evaluate these characteristics as it is believed that they can affect the adoption of $\mathrm{AI}$ as a breeding technology.

\section{Gender of Farmers}

About $26 \%$ and $74 \%$ of participated farmers in the interview in the four regions were female and male, respectively, which is also average values for the four regions combined. These figures for Oromia, SNNP and Tigray regions were $14 \%$ and $86 \%, 46 \%$ and $54 \%$, and $17 \%$ and $83 \%$, respectively.

The overall proportion of male-headed dairy households (74\%) was much higher than that of female-headed dairy households (26\%). In most parts of the country, it is a norm that the household is represented by the husband if he is alive, otherwise the household is represented by the wife in the absence of her husband due to various reasons. Though the contribution of women in terms of dairy cattle husbandry and management is significant in a dairy household, their role in the process of household-related decision making in the male-headed households was insignificant.

No significant difference observed in the present study between male and female farmers in terms of the number of years that they use AI technology for breeding purpose. However, gender is thought to be among the major factors which influence technology adoption, especially of agricultural technologies. However, previous research reports showed mixed evidence regarding the role of gender in the process of technology adoption. For instance, Doss and Morris (2001) and Fleming and Yala (2001) didn't see gender difference in the adoption rate of improved maize technology in Ghana and coffee production technology in Papua Guinea, respectively. Bisanda \& Mwangi, (1996) on the other hand, observed a strong relationship between gender and technology adoption. Abdallah (2011), on the other hand, reported a negative relationship between AI adoption and gender in Tanzania where women farmers had a better adoption rate.

\section{Age of Farmers}

The age of dairy farming household heads was significantly different $(\mathrm{P}<0.0001)$ among the four regions with the highest age (45.62 years) recorded in Tigray region and the lowest ( 40.38 years) in Oromia. The average age of farmers for Amhara and SNNP regions was 47.16 and 45.21, respectively with an overall average age of 45.62 years. No significant difference observed in the age of SNNP and Amhara region dairy farming household heads.

The average age of farmers reported in this study is not high rather it is in the working-age group. As indicated in Adesiina and Baidu-Forson (1995), Dehninet et al. (2014); McNamara et al., 1991; Peter et al. (2012); and Quddus (2012) age of farmers is among the most important variable which is believed to negatively influence adoption of agricultural technologies. Age is also said to be a primary latent characteristic in the decision-making process for technology adoption. The younger generation is better educated, more flexible and exposed to technology-related information and thus believed to try and adopt agricultural technologies more quickly than older ones. This is mainly because older farmers are conservative and may not want to take risk by trying out a new technology (Audrey, 2014; Peter et al., 2012). Feder et al. (1985) indicated that as the age of farmers increased farmers will become more reluctant to adopt new technologies. This contradicts findings by Abdallah (2011) and Kaaya et al. (2005) who reported a positive relationship between age and AI technology adoption and Joseph and Ango, (2014) who reported a non-significant relationship between the two variables. The average age of farmers reported in the present study is comparable with other reports such as Quddus (2012) who reported 57\% of dairy farmers in Bangladesh belonged to 30-49 years of age and Potdar et al. (2018) who reported an average age of farmers 41 years in India. 


\section{Educational Status of Farmers}

About $81 \%, 58 \%, 62 \%$ and $82 \%$ of the household heads attained primary level education or below in Amhara, Oromia, SNNP and Tigray regions, respectively. The proportion of farmers who attained secondary level of education in Amhara, Oromia, SNNP and Tigray regions was $12 \%, 28 \%, 23 \%$ and $17.5 \%$, respectively with an overall average of $20 \%$. Similarly, about $7 \%, 14 \%, 15 \%$ and $1 \%$ of farmers completed either technical education or above in Amhara, Oromia, SNNP and Tigray regions, respectively with an overall average of 9\%.

Nearly $30 \%$ of farmers were non-educated or illiterate in the four studied regions. This confirms that dairying is being practiced by non-professionals using the traditional way. However, dairying can be used as a source of income to the household in addition to improving household nutrition if proper dairy husbandry and management system is applied. Previous research reports indicated that education level of farmers has significant effect on technology adoption as it creates a favourable mental attitude for the acceptance of new practices especially of information-intensive and management-intensive practices and it can reduce the amount of complexity perceived in a technology thereby increasing a technology's adoption (Abdallah, 2011; Borden et al., 2017; Kayaa et al., 2005; Waller et al., 1998; Caswell et al., 2001; Joseph and Ango, 2014; Pankaj and Nayaran, 2016; Sime et al., 2014). The more educated farmers were more likely to adopt the recommended technology. Quddus, (2012) also reported that secondary and higher educated farmers were nearly 10 times more likely to adopt improved technologies compared to illiterate farmers in Bangladesh. Therefore, the low level of livestock-related technology adoption such as AI technology in the studied regions might be related to the education level of farmers. Strategies need to be designed to improve the technology adoption rate by educating farmers to a certain level.

\section{Family Size}

Very high significant difference $(\mathrm{P}<0.0001)$ observed in the family size among the four regions $($ Table 4$)$. The average dairy farming household's family size in the four studied regions was 6.18 persons per household with the highest (6.9) and lowest (5.34) in SNNP and Amhara regions, respectively. The average number of male household members in the four regions was 3.21 while the female was 3.05 .

Table 4. Family size of dairy farming households in Amhara, Oromia, SNNP and Tigray Regions

\begin{tabular}{lcccc}
\hline Region & $\mathrm{N}$ & $\begin{array}{c}\text { Male } \\
\text { Mean } \pm \text { SE }\end{array}$ & $\begin{array}{c}\text { Female } \\
\text { Mean } \pm \text { SE }\end{array}$ & $\begin{array}{c}\text { Total } \\
\text { Mean } \pm \text { SE }\end{array}$ \\
\hline Amhara & 103 & $2.91 \pm .013^{\mathrm{b}}$ & $2.55 \pm 0.14^{\mathrm{b}}$ & $5.34 \pm 0.24^{\mathrm{b}}$ \\
Oromia & 104 & $3.62 \pm 0.22^{\mathrm{a}}$ & $3.30 \pm 0.19^{\mathrm{a}}$ & $6.79 \pm 0.35^{\mathrm{a}}$ \\
SNNP & 104 & $3.39 \pm 0.15^{\mathrm{a}}$ & $3.51 \pm 0.14^{\mathrm{a}}$ & $6.90 \pm 0.21^{\mathrm{a}}$ \\
Tigray & 101 & $2.92 \pm 0.14^{\mathrm{b}}$ & $2.85 \pm 0.14^{\mathrm{b}}$ & $5.71 \pm 0.21^{\mathrm{b}}$ \\
\hline Total & 412 & $3.21 \pm 0.08$ & $3.05 \pm 0.08$ & $6.18 \pm 0.13$ \\
\hline
\end{tabular}

Means with different superscripts in the same column are significantly different $(p<0.05)$

The overall average number of male and female household members was 3.21 and 3.05 per household, respectively. Family size has a direct relationship with labor availability required for agricultural activities of the household such as dairying. The average family size reported in the present study is higher than the CSA 1994 census report of 4.8 (CSA, 1999). Mixed relationship observed between family size and AI technology adoption reported in previous studies. Dehninet et al., (2014) observed a positive relationship between the two variables. However, a negative relationship between family size and technology adoption reported in Oromia region, Ethiopia (Sime et al., 2014). Abdallah (2011) and Joseph and Ango, (2014), on the other hand, did not observe a significant difference between adopters and non-adopters taking family size as factor. The report of Borden et al. (2012) revealed big families (6-7 members) tend to use AI technology and small families (up to three members) preferred to use natural service.

\section{Dairy Households Income}

Total household income, income from off-farm activities as well as from livestock related sources in the four regions is summarized in Table 5 below. Very high significant difference $(\mathrm{P}<0.0001)$ observed in income from off-farm activities among the four regions with a mean income of 2,111.72 ETB per household per month. Total household income, income from sale of livestock and livestock products was also significantly different $(p<0.05)$ among the four regions. The highest income (5,500 ETB) per household per month from livestock sale and livestock products was recorded in Tigray region whereas the least (1,284 ETB) was in Amhara region. 
Table 5. Income (Mean ETB \pm SE) from different sources per household per month (July 2018) in Amhara, Oromia, SNNP and Tigray regions

\begin{tabular}{lccccc}
\hline Region & $\mathrm{N}$ & Total & Off-farm & Livestock Sale & Livestock Products \\
\hline Amhara & 106 & $5686.07 \pm 385.75^{\mathrm{b}}$ & $2535.55 \pm 264.91^{\mathrm{NS}}$ & $1866.28 \pm 172.80^{\mathrm{b}}$ & $1284.23 \pm 169.20^{\mathrm{b}}$ \\
Oromia & 104 & $6424.30 \pm 404.78^{\mathrm{ab}}$ & $2303.65 \pm 308.39^{\mathrm{NS}}$ & $2721.90 \pm 233.83^{\mathrm{a}}$ & $1398.76 \pm 137.77^{\mathrm{a}}$ \\
SNNP & 105 & $8019.97 \pm 1160.25^{\mathrm{a}}$ & $1778.76 \pm 233.88^{\mathrm{NS}}$ & $2026.63 \pm 232.59^{\mathrm{b}}$ & $4214.57 \pm 962.06^{\mathrm{b}}$ \\
Tigray & 104 & $7324.67 \pm 441.08^{\mathrm{ab}}$ & $1823.94 \pm 281.93^{\mathrm{NS}}$ & $2725.58 \pm 208.19^{\mathrm{a}}$ & $2775.14 \pm 223.08^{\mathrm{a}}$ \\
\hline Total & 419 & $6860.89 \pm 342.33$ & $2111.72 \pm 137.09$ & $2332.12 \pm 107.87$ & $2417.05 \pm 259.11$ \\
\hline
\end{tabular}

Since household income is related to the income tax issue, farmers might not tell their actual income. Thus, it is expected that the actual average monthly total income might be higher than the reported figure. Since it is beyond the scope of this study, we didn't use different methodological approaches to examine and know the actual household income. Though income is not the only variable of interest to examine factors affecting the adoption level of AI technology, the present study confirms a significant positive correlation ( 0.195$)$ between total monthly family income and number of years that a dairying household have been used AI technology. It is also confirmed in this study that dairying was among the major source of income for the dairying households in the studied regions. Previous research reports also indicated that household income has a positive relationship with the adoption of agricultural technologies (Watcharaanantapong et al., 2014; Walton et al., 2010). Investing in new and innovative technologies carry higher entry costs and more risk than already established technologies (Diederen et al., 2003). Income in most cases has a relationship with the affordability of inputs and other costs. As indicated in Kayaa et al. (2005) AI cost has a negative relationship with AI technology adoption in Uganda. Dehninet et al. (2014) Peter et al. (2012) and Sime et al. (2014) reported a negative relationship between off-farm income and AI technology adoption and a positive relationship between income from sale of dairying and AI technology adoption. AI is much labor-intensive than the use of bull as AI requires significant time and labor to observe and detect cows in heat and to take the necessary action following the heat. However, this may not be a case in Ethiopia as AI service is highly subsidized by the government.

\section{Size of Cattle and Other Livestock Species}

Very high significant difference $(\mathrm{P}<0.0001)$ was observed in the number of heifers, and male and female calves owned per household among the four regions (Table 6) with highest number of heifers (1.28) in SNNP, male (1) and female (1) calves in SNNP and Oromia regions, respectively. Significant difference $(p<0.05)$ also observed in milking cows, dry cows and total cattle herd size among regions with the highest cattle herd size (7.21) being recorded in the Oromia region.

Table 6. Cattle herd size (Mean \pm SE) of the dairy farming households in Amhara, Oromia, SNNP and Tigray regions

\begin{tabular}{lccccccc}
\hline Region & $\mathrm{N}$ & Total cattle & Milking cows & Dry cows & Heifers & Female calves & Male calves \\
\hline Amhara & 105 & $5.50 \pm 0.29^{\mathrm{b}}$ & $1.25 \pm 0.11^{\mathrm{ab}}$ & $0.69 \pm 0.07^{\mathrm{b}}$ & $0.62 \pm 0.07^{\mathrm{b}}$ & $0.88 \pm 0.09^{\mathrm{ab}}$ & $0.78 \pm 0.07^{\mathrm{b}}$ \\
Oromia & 104 & $7.21 \pm 0.51^{\mathrm{a}}$ & $1.63 \pm 0.13^{\mathrm{b}}$ & $1.44 \pm 0.15^{\mathrm{a}}$ & $1.28 \pm 0.13^{\mathrm{a}}$ & $0.86 \pm 0.11^{\mathrm{ab}}$ & $1.02 \pm 0.10^{\mathrm{a}}$ \\
SNNP & 104 & $4.88 \pm 0.65^{\mathrm{b}}$ & $1.73 \pm 0.32^{\mathrm{a}}$ & $1.00 \pm 0.17^{\mathrm{b}}$ & $1.06 \pm 0.15^{\mathrm{a}}$ & $0.99 \pm 0.19^{\mathrm{a}}$ & $0.52 \pm 0.08^{\mathrm{c}}$ \\
Tigray & 103 & $4.72 \pm 0.32^{\mathrm{b}}$ & $1.08 \pm 0.12^{\mathrm{b}}$ & $0.92 \pm 0.12^{\mathrm{b}}$ & $0.72 \pm 0.09^{\mathrm{b}}$ & $0.57 \pm 0.08^{\mathrm{b}}$ & $0.45 \pm 0.08^{\mathrm{c}}$ \\
\hline Total & 416 & $5.58 \pm 0.28$ & $1.42 \pm 0.10$ & $1.00 \pm 0.07$ & $0.91 \pm 0.06$ & $0.82 \pm 0.06$ & $0.70 \pm 0.04$ \\
\hline
\end{tabular}

Means with different superscripts in the same column are significantly different $(p<0.05)$

Average chicken number per household was 4.4 with no significant difference $(p>0.05)$ observed among the four regions. However, the difference in the average number of sheep and goat was significant $(p<0.05)$ among the four regions with an average number of 1.84 and 0.43 per household, respectively. Sample farmers from Tigray region owned the highest number of sheep (3.58) and goat (1.04) per household compared with the other regions. The average number of sheep was $0.95,1.33$ and 1.52 and goats per household in Amhara, Oromia, and SNNP regions was 0.95 and $0.47,1.33$ and $1.33,1.52$ and 0.04 and 3.58 and 1.04 , respectively.

\section{Access to Extension Service}

The present study demonstrates $76 \%$ of farmers in the four regions had access to livestock extension services during the study period. Access to livestock extension is an important factor that positively affects the adoption of livestock-related technologies (Abdallah, 2011; Dehinenet et al., 2014; Kayaa et al., 2005; Sime et al., 2014) and management practices which can later affect productivity parameters. The result obtained in the present study seems very high as the study focused on those who had at least one kind of extension service. Access, on the other hand, doesn't mean practicing a given technology or management practices. Further research is needed to examine the degree of access and application of extension system by looking at the different types of livestock extension systems. The proportion of farmers who had access to extension system is higher when compared with the report of Dehinenet et al. (2014) in Oromia region where only 66\% had access to extension service. It is also higher than 
Bangladesh and Tanzania farmers where only $11 \%$ and $20 \%$ of farmers reported to have access to extension service (Quddus, 2012; TLMI, 2015). Similarly, the CSA (CSA, 2018) reported that only $9.63 \%$ of farmers in the country were engaged in dairy development packages. This is extremely low when it comes to the application of improved dairy-related technologies and management practices.

\section{Experience of Farmers in Dairying}

As understood from sample respondent households, the establishment of dairying is in an increasing trend with most dairy farms being established in the last nine to ten years $(2009-2018)$. About $48 \%$ of farms in Amhara, $45 \%$ in Oromia, 24\% in SNNP and 55\% in Tigray regions established between 2009 and 2018 (Figure 1).

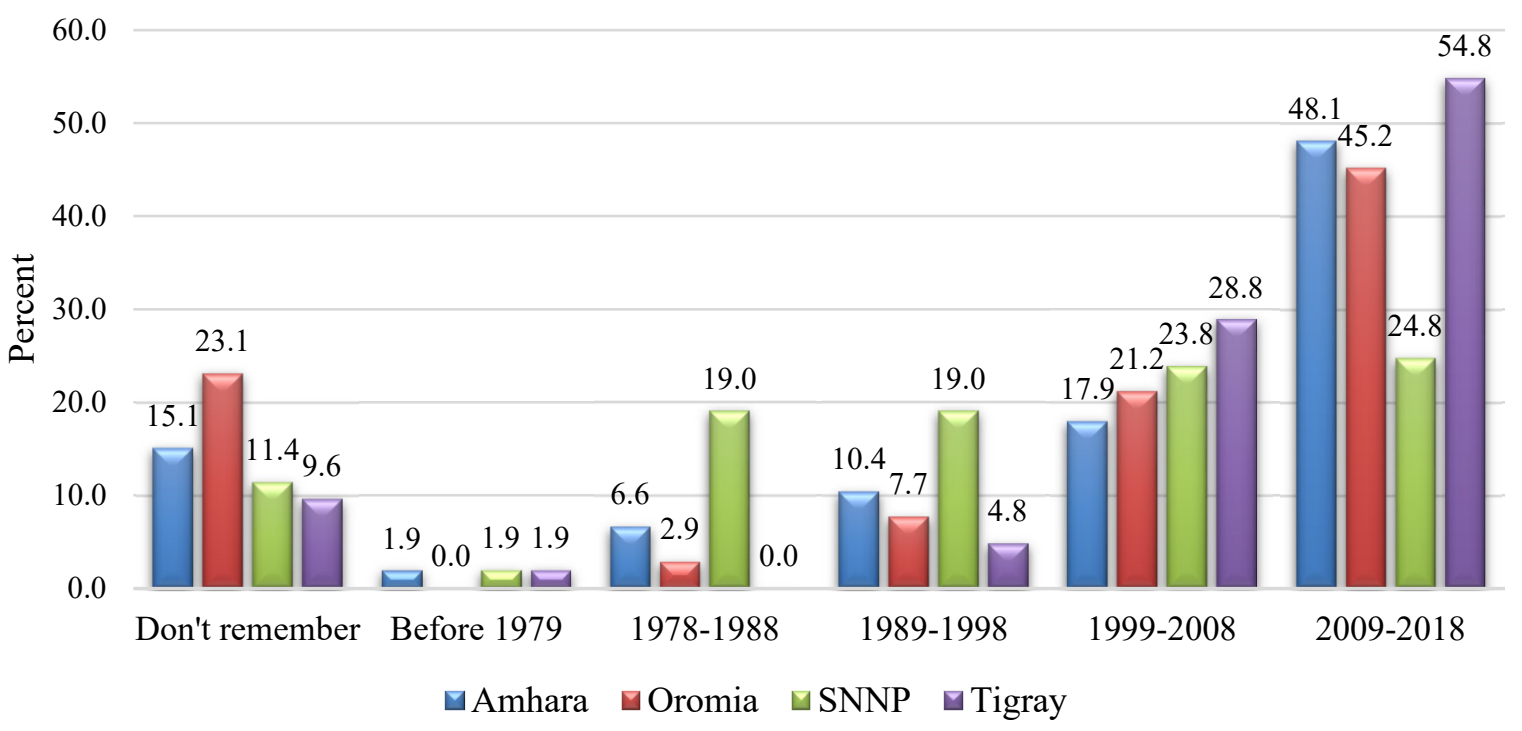

Figure 1. Farmers experience in dairying in Amhara, Oromia, SNNP and Tigray regions

About $78 \%$ of dairy farms are established in the last three decades. This clearly shows either a significant proportion of farms are established in the last ten years or dairying may not be kept for a longer period due to various reasons. The increasing demand for milk and milk products especially in urban and peri-urban areas seen in the last two decades can be mentioned as a driving force for the establishment of a significant proportion of dairy farms in the last two to three decades. Future research shall focus on identifying factors that hindering farmers to keep their dairying for a longer period if this problem exists in the country. Land and labor shortage, increasing trend of the price of feed, veterinary and other input might be among important factors in this regard. The experience of farmers reported in the present study agrees with the experience of farmers in some other countries such as Bangladesh where about $66 \%$ of dairy farmers had less than 10 years of experience in dairy farming Quddus (2012). However, Lawrence et al. (2013) reported longer (23 years) dairy farming experience in Kenya. The present study confirms a significant positive correlation $(\mathrm{r}=0.362)$ between experience in dairying and the number of years that farmers have been using AI technology. This positive correlation agrees with previous research reports where it is indicated that farmers' experience in dairying is interrelated with technology adoption (Abdallah, 2011; Dehninet et al., 2014; Joseph and Ango, 2014; Quddus, 2012). In contrary to the present study a negative correlation reported between experience and adoption of AI technology in Uganda (Kayaa et al., 2005; Masoud and Asghar, 2011; Sime et al., 2014).

\section{Experience of Farmers with AI Technology}

Adoption of improved dairy husbandry and management practices are among the most important factors for increased milk productivity (Khanal et al. 2010). However, most farmers are reluctant to adopt improved husbandry and management practices. Thus, the present study confirms the adoption level of these practices was very low in the four studied regions.

Proper breeding strategy and high level of AI adoption, on the other hand, are vital to establish an efficient and profitable dairy sector Quddus (2012). About 62\% of farmers in the four regions received artificial insemination service either once or twice in a year with an average AI service number of 2.14 . Only $25 \%$ of respondents in the four regions received insemination service thrice or more. The study population is those farmers who received AI service at least once. Thus, it is impossible to make comparisons with those who have never used the technology and draw conclusions on the adoption of AI technology. The average number of milking and dry cows reported in the four regions was 1.42 and 1.0, respectively. The number of AI services is directly related to the number of dairy cattle that need the service, availability, and accessibility of the service. Thus, the low number 
of AI services might be directly related to the small number of dairy cattle that potentially need the service.

Farmers in the four studied regions have been using AI service for an average of 5.4 years. The experience of farmers in AI technology reported in the present study is very similar to Hammonds (2016) in Bangladesh where farmers had been using for about 5.2 years. With reported 2.14 numbers of inseminations per year and 5.38 years of experience in AI technology, farmers in the four studied regions received an average of 11.5 inseminations since they began using AI technology. This is also very similar to Bangladesh farmers whey they performed an average of 10 inseminations since they start using this breeding technology (Hammonds, 2016). AI technology is introduced in the country in the 1960s and 1970s; however, farmers' experience with AI technology is very low considering the time of its introduction. The technology is being provided in the country for about 50 years, but the present study revealed that the technology was being utilized by farmers only for an average of about 5 years. Utilization of AI service for a longer time has paramount importance to establish good dairy herd and improve the genetic make-up of the dairy herd. Reliable and sustainable AI service delivery system in this regard is vital to bring the desired result in AI-based crossbreeding programs. However, farmers' experience with AI technology reported in the present study makes the sustainability and reliability of AI service delivery system in the country questionable. Factors contributed to the low level of experience with AI technology need to be further investigated. Intermittent service delivery system, intermittent input supply system, lack of awareness among farmers, short period of farmers experience for the dairy cattle and low level of livestock extension system can be mentioned as factors that hindering farmers to use AI technology for longer period than reported in this study. Quddus (2012) suggested that lack of basic equipment and negligible AI services, lack of knowledge among farmers about health management and proper feeding of animals are constraints to adopt AI technology and other improved agricultural technologies. Sime et al., (2014), on the other hand, reported a negative relationship between years in AI and adoption of AI technology. This is a different perspective regarding the experience of farmers in AI and its adoption.

The present study clearly shows that farmers do not have extensive experience with AI technology as most farmers received the service only once or twice a year. The number of insemination service alone do not show the efficiency of the service and thus all the services might not be resulted in conception. Therefore, it may be vital to relate insemination services provided to farmers with their satisfaction. Only $9 \%$ of farmers in the four regions rated their AI technicians as excellent, $86 \%$ as very good and good. The level of satisfaction was measured without taking the different criteria used to measure satisfaction level. Further study shall be conducted to investigate the level of satisfaction based on clear and measurable criteria. Since private AI service delivery system was not available in most parts of the study areas, farmers rated their satisfaction based on the experience they had with public AI technicians. The present finding agrees with Sisay et al. (2017) who reported $85 \%$ of farmers were satisfied with AI service delivery system in West Shewa zone of Ethiopia. Unlike the present finding, Zerihun et al. (2013) reported 69\% of farmers in Mecha district of Amhara region were dissatisfied with the overall AI service delivery system and its efficiency. This was mainly due to unreliable and inconsistent AI service. Similarly, 41\% of farmers in Jimma district were not satisfied by AI service delivery system (Nuraddis et al., 2014). Yohanis and Tilahu (2018) also reported more than 50\% of farmers in Adama Town of Oromia region were not satisfied with the overall AI service delivery system. The same authors mentioned discontinuation of the service during weekends and holidays, shortage of AI technicians, shortage of necessary inputs and long-distance of insemination sites as major reasons for the low satisfaction rate in the AI delivery system. Conception failure is also mentioned as a critical factor for the low satisfaction rate and adoption of AI technology in many parts of the country (Gebregiorgis et al., 2016; Nuraddis et al., 2014; Zerihun et al., 2013; Tessema and Atnaf, 2015; Sisay et al., 2017; Yohanis and Tilahun, 2018).

Adoption of AI technology should be integrated with the adoption of other improved dairy technologies such as improved health management, housing, and feeding. About $66 \%$ of farmers in the four studied regions had permanent type of dairy cattle housing. However, the comfort, hygiene, and cleanliness of the dairy cattle houses were questionable. Nearly $62 \%$ of farmers were practicing either mainly stall feeding or mainly stall feeding with some grazing type of feeding system. About $68 \%, 75 \%$ and $69 \%$ of farmers in the studied regions were practicing deworming, external parasite treatment and vaccination, respectively. Only $12 \%$ of farmers in the four regions were keeping records about any aspect of their dairying. On the contrary, nearly $70 \%$ of farmers in Uganda keep records of AI (Camilla, 2013). The application of improved management practices seems good in the studied regions. Further study needs to be conducted to investigate the level of application of each of the management practices and to establish a relationship with productivity and other economically important parameters.

\section{CONCLUSION AND RECOMMENDATION}

Serious problem is not observed both in the training curriculum and duration of AI technicians training. However, the criteria used to select candidate AI technicians need to be revised again. AI is an art and science and needs background theoretical and if possible practical knowledge on female cattle reproductive anatomy and physiology. Thus, considering candidate AI technicians with this background knowledge will help in producing efficient and competent AI technicians. Though women are said to be passionate and responsible in their job, the engagement 
of women in AI service delivery is very insignificant due to cultural taboos and biological issues. Much work must be done to increase their engagement as AI technician and special emphasis should be given to them while providing AI equipment, transportation facilities and incentives.

One of the major factors for the success of AI service delivery system is the experience of AI technicians. The turnover rate of AI technicians is high in all studied regions due to their low monthly income, discouraging carrier structure and poor recognition and reward system. These factors lead to low level of job satisfaction among AI technicians. Thus, strategies need to be designed and implemented to motivate and retain AI technicians in their position and further studies should identify factors contributing to the high turn-over rate of AI technicians in the country.

Though the study demonstrates high access to livestock extension service system, farmers in the four regions do not have long years of experience in dairying due to various reasons. Unreliable AI service, increasing trend of feed prices, shortage of labor and land are among factors contributing to the short experience of farmers in dairying. Utilization and adoption of AI technology and experience in dairying are interrelated. Therefore, to use and adopt AI technology, farmers are expected to have long years of dairying experience and vice versa. On top of this, emphasis should be given for reliability, quality, availability, and affordability of the service as these factors significantly affect the adoption of the technology.

\section{Conflict of Interests}

The authors have not declared any conflict of interests.

\section{Acknowledgments}

This study is made possible through the support of Land O'Lakes Venture 37 and the authors greatly acknowledge the organization for allowing us to use data for academic purposes. The authors would also thank AI technicians, farmers, regional bureau livestock experts for their active participation and required support.

\section{REFERENCE}

Abdallah Emil Mlemba. (2011). Factors Affecting Adoption of Artificial Insemination Technology by Dairy Farmers in Kinondoni District. A Dissertation Submitted to Sokoine University of Agriculture. Morogoro, Tanzania.

Adesiina, A A and Baidu-Forson, J (1995). "Farmers' Perceptions and Adoption of New Agricultural Technology: Evidence from Analysis in Burkina Faso and Guinea, West Africa Journal of Agricultural Economics.13:19.

Alexander P A B D, Abeygunawardena H, Perera B M A O and Abeygunawardena I S (1998). Reproductive Performance and Factors Affecting the Success Rate of Artificial Insemination of Cattle in Up-country Multiplier Farms of Sri Lanka. Tropical Agricultural Research Vol. 10 1998,356-371. IAEA/FAO Joint Division, Vienna, Austria.

Audrey Amagove Kinyangi (2014). Factors Influencing the Adoption of Agricultural Technology among Smallholder Farmers in Kakamega North Sub-County, Kenya. A research project submitted in partial fulfilment of the requirements for the award of the Degree of Master of Arts in Project Planning and Management of the University of Nairobi.

Borden Mushonga, Jean P Dusabe, Erick Kandiwa, Evison Bhebhe, Gervais Habarugira, Alaster Samkange (2017). Artificial Insemination in Nyagatare District: Level of Adoption and the Factors determining its Adoption. Alexandria Journal of Veterinary Sciences. Vol. 55 (1):1-7.

Camilla Eklundh (2013). The use of artificial insemination in dairy farms in urban/peri-urban Kampala, Uganda a study of knowledge, attitude and practices. Swedish University of Agricultural Sciences, Faculty of Veterinary Medicine and Animal Science, Degree project, Veterinary Program, Uppsala 2013.

Caswell, M, K Fuglie, C Ingram., S Jans and Kascak, C (2001). Adoption of Agricultural production practices: Lessons learned from the US. Department of Agriculture area studies project. Washington DC. US Department of Agriculture. Resource Economics Division, Economic Research service, Agriculture Economic Report No. 792.

CSA (2018). Federal Democratic Republic of Ethiopia Central Statistical Agency. Agricultural Sample Survey, 2017/18 [2010 E.C.], Volume II, Report on Livestock and Livestock Characteristics (Private Peasant Holdings). Statistical Bulletin 587. April 2018.

Dehinenet G, Mekonnen H, Kidoido M, Ashenafi M and Guerne Bleich E (2014). Factors influencing adoption of dairy technology on small holder dairy farmers in selected zones of Amhara and Oromia National Regional States, Ethiopia. Discourse Journal of Agriculture and Food Sciences. Vol. 2(5): 126-135.

Desalegn G/Medhin, Merga Bekana, Azage Tegegne, and Kelay Belihu (2009). Status of artificial insemination service in Ethiopia. In: The $17^{\text {th }}$ Annual Conference of the Ethiopian Society of Animal Production (ESAP), Sept 24-26, 2009 Addis Ababa, Ethiopia, pp.87-104. 
Diederen, P, van Meijl, H, Wolters, A, \& Bijak, K (2003). Innovation Adoption in Agriculture: Innovators, Early Adopters and Laggards. Cahiers D’Economie Et Sociologie Rurales 67 (2003): 30-50.

Doss Cheryl R., Morris Michael L. (2001). How does gender affect the adoption of agricultural innovations? The case of improved maize technology in Ghana. Agricultural Economics 25 (2001) 27-39

Gebregiorgis Ashebir, Alemselam Birhanu, Tadesse Gugsa (2016). Status of Artificial Insemination in Tigray Regional State, "Constraints and Acceptability under Field Condition". Journal of Dairy Veterinary and Animal Research. 3(3): 00078. DOI: 10.15406/jdvar.2016.03.00078

Guldford, J P, Fricther, B (1973). Fundamental Statistics in Psychology and Education, 5th edition. McGraw Hill, ISBN 0070251487.

Feder G R, Just R E and Zilberman D (1985). Adoption of agricultural innovation in developing countries: A survey. Econ Dev. and Cult. Change 33: 255-298.

Fleming, E and Yala, C (2001). Policy Options for the Tree Crop Industries in Papua New Guinea, Monograph No. 81, Australian Centre for International Agricultural Research, Canberra, 211

Galv med (2011). The gender and social dimensions to livestock keeping in Africa. Galv med - Protecting Livestock - Saving Human Life.

Hammonds Tara (2016). A Study of the Integration of Artificial Insemination into the Dairy Sector of the Alaotra Mangoro Region of Madagascar. Independent Study Project (ISP) Collection. 2420. https://digitalcollections.sit.edu/isp_collection/2420

Joseph Dauda Bayei and Ango Inuwa Nache (2014). The Effect of Socio-Economic Characteristics of Cattle Farmers on the Adoption of Artificial Insemination Technology In Kaduna State of Nigeria. IOSR Journal of Agriculture and Veterinary Science (IOSR-JAVS). Volume 7, Issue 9 Ver. II:11-17

Kaaya H Bashaasha B Mutetikka D (2005). Determinants of Utilisation of Artificial Insemination (AI) Services among Ugandan Dairy Farmers. African Crop Science Conference Proceedings, Vol. 7. 561-567.

Khanal A R, Gillespie J and MacDonald J (2010). Adoption of technology, management practices, and production system in US milk production. J. Dairy Sci. 93: 60126022.

Kinyua J (2016). Evaluation of Artificial Insemination Services Performance in a Smallholder Dairy Herd Under Extensive Management: A Case Study of KALRO- Lanet Herd, Kenya. Weber Agricultural Research \& Management 2 (191): 692-694, 2016. https://weberpub.org/abstract/abstract_warm_191.htm

Lawrence F G, HM Mutembei, J Lagat, J Mburu, J Amimo and A M Okeyo (2015). Constraints to use of breeding services in Kenya. Inter J Vet Sci, 4(4): 211-215. www.ijvets.com

McNamara, K.T., Wetzstein, M.E. and Douce, G.K. (1991) Factors Affecting Peanut Producer Adoption of Integrated Pest Management. Applied Economics Perspective and Policy, 13, 129-139. https://doi.org/10.2307/1349563

Masoud Rezaei and Asghar Bagheri (2011). Comparative analysis of characteristics of adopters and non-adopters of artificial insemination in Ardabil Province of Iran. Emir. J. Food Agric. 2011. 23 (5): 466-472

Ntombizakhe Mpofu (2002). The importance of breeding infrastructure and support services: the success/failure of artificial insemination as a method of disseminating genetic material to smallholder dairy farmers in southern Africa. Animal Genetics Training Resource. http://agtr.ilri.cgiar.org/index.php?option=com_content\&task=view\&id=78\&Itemid=95

Nuraddis Ibrahim, Reta Hailu, and Abidu Mohammed. (2014). Assessment of Problems Associated with Artificial Insemination Service in Selected Districts of Jimma Zone. Journal of Reproduction and Infertility 5 (2): 37 44,2014

OECD (2019). Working age population (indicator). doi: 10.1787/d339918b-en (Accessed on 22 July 2019 from https://data.oecd.org/pop/working-age-population.htm

Pankaj Raj Dhital, Narayan Raj Joshi (2016) Factors Affecting Adoption of Recommended Cauliflower Production Technology in Nepal. Turkish Journal of Agriculture - Food Science and Technology, 4(5): 378-383

Peter Lundqvist, Stefan Pinzke and Bengt Gustafsson (1992). Ergonomic factors in the work situation for AI technicians on animal farms. Advances in Industrial Ergonomics IV. Edited by Shrawan Kumar. Taylor and Francis.

Peter Howley, Cathal O Donoghue, Kevin Heanue (2012). Factors Affecting Farmers’ Adoption of Agricultural Innovations: A Panel Data Analysis of the Use of Artificial Insemination among Dairy Farmers in Ireland. Journal of Agricultural Science; Vol. 4, No. 6; 2012.

Potdar V V, Khadse J R and Swaminathan M (2018). Impact Assessment Study of the Dairy Farmers in Bihar, Uttar Pradesh and Maharashtra. Int J Anim Sci. 2018; 2(5): 1035.

Quddus M A (2012). Adoption of dairy farming technologies by small farm holders: practices and constraints. Bang. J. Anim. Sci. 2012. 41 (2): 124-135

Roque, A (2011). People Find Their Calling in Artificial Insemination. Available from: https://business.inquirer.net/482/people-find-their-calling-in-artificial-insemination accessed on 25-05-2016. 16. 
SAS (2004). Users Guide. Version 6.12. Statistical Analysis System (SAS) Institute, Inc. Carry, NC.

Senger, P L, Hillers, K L Mitchel, J R, fleming, W N, Darlington, R L (1984). Effects of Serum treated Semen, Bulls and Herdsmen-inseminators on Conception to First Service in large Commercial Dairy herds, Dairy Science Journal. (1984) 686-693.

Sime S. Tefera, Job K Lagat and Hillary K Bett (2014). Determinants of Artificial Insemination Use by Smallholder Dairy Farmers in Lemu-Bilbilo District, Ethiopia. International Journal of African and Asian Studies - An Open Access International Journal Vol.4 2014.

Sisay, W, Tamene, D, Worku, G, Kidanu,D, Getahun B and Nuraddis I (2017). Evaluation of Artificial Insemination Efficiency in and Around Ejere District, Western Shoa Zone, Ethiopia.Journal of Reproduction and Infertility, 8(3): 66-71.

SPSS (2011). Statistical Procedures for Social Sciences (SPSS). IBM® SPSS® Statistics 20. IBM Corp. Chicago, USA.

Souames S, Hanzen C, Detilleux J, Kaidi R (2015). Survey of artificial insemination practices in Algeria. Research Journal of Veterinary Practitioners. 3(1): 1-9. Retrieved from http://nexusacademicpublishers.com/uploads/files/Nexus_528.pdf

Tessema Reta and Atnaf Alebie (2015). Assessment of Problems Associated with Artificial Insemination Services in and Around Gondar Town, North West Ethiopia. Journal of Reproduction and Infertility 6 (2): 22-26.

Waller, B E , Hoy, C W, Henderson,.J L, B Stinner and Welty, C (1998). "Matching Innovations with Potential Users: A Case Study of Potato IPM practices.” Agriculture, Ecosystems and Environment.70 (1998):203-215.

Walton, J C, J.A. Larson, R K Roberts, D M Lambert, B C English, S L Larkin, M C Marra, S W Martin, K W Paxton, J M. Reeves (2010). Factors Influencing Farmer Adoption of Portable Computers for Site-Specific Management: A Case Study for Cotton Production. Journal of Agricultural and Applied Economics 42(2) (2010): 193-209.

Watcharaanantapong, P, R K Roberts, D M. Lambert, J A. Larson, M Velandia, B C. English, R M Rejesus, C Wang (2014). Timing of Precision Agriculture Technology Adoption in US Cotton Production. Precision Agriculture 15 (2014): 427-446.

Wytze Brandsma, Dawit Mengistu, Binyam Kassa, MahletYohannes, Jan van der Lee (2012). The Major Ethiopian Milk sheds. An assessment of development potential Milk value chain, stakeholders, production potential, market potential, and possible intervention areas. Wageningen University and SNV Ethiopia.

Ybañez AP, Ybañez R H D, Caindec MO, Mani L V, Abela J V, Nuñez E S, Royo J T, Lopez I F M (2017). Profile and artificial insemination practices of technicians and the artificial insemination success rates in Leyte, Samar, and Biliran, Philippines (2011-2015), Veterinary World, 10(2): 181-186. www.veterinaryworld.org/Vol.10/February-2017/8.pdf

Yohanis Kebebew and Tilahun Bekele (2018). Assessment of Efficiency and Major Constraint of Artificial Insemination Service in Small Holder Dairy Farmers in and around Adama Town. Int. J. Adv. Res. Biol. Sci. (2018). 5(7): 88-99.

Zerihun Baheriw, Malede Birhan, and Tewodros Fentahun (2013). Assessment on Problems Associated with Artificial Insemination Services in West Gojjam Zone, Ethiopia. Advances in Biological Research 7 (2): 59 66. 